\title{
O indivíduo: sujeito de Direito Internacional Público?
}

\author{
Beatriz Schiffer Durães*
}

$\mathrm{Na}$ abordagem do tema "sujeito de Direito Internacional Público", pretende-se o esclarecimento de quem sofre diretamente responsabilidades por uma conduta incompatível com a norma internacional e quem tem legitimidade direta para reclamar contra toda violação dessa norma. $\mathrm{Ou}$ seja, nem todos os entes beneficiados por uma prescrição normativa internacional ou todos aqueles em que esta imponha uma conduta são sujeitos de Direito Internacional Público. Segundo Soerensen, ${ }^{1}$ "são sujeitos de Direito Internacional Público aqueles entes que além de serem destinatários das normas têm legitimidade para reclamar pelo incumprimento das normas ou podem incorrer em responsabilidade se são eles que as infringem".

A Comunidade Internacional tem como principal fator a dependência recíproca dos povos sob o ponto de vista dos interesses econômicos, morais e intelectuais. O Direito Internacional Público clássico apoiava-se basicamente numa sociedade internacional de estrutura interestatal cuja função era o de regular as relações entre os Estados, sujeitos por excelência, estes amplamente capacitados para reclamar por violações internacionais assim como também susceptíveis de responsabilidade internacional. E a estrutura que ainda sé mantém, na maioria dos casos, é a de que se um Estado comete um ilícito internacional em prejuízo a um estrangeiro, o prejudicado não está habilitado a propôr uma reclamação no plano internacional contra o Estado infrator. O particular não pode dirigir uma reclamação direta na esfera internacional contra o Estado autor do fato ilícito nem pode levá-lo ante uma juris-

1 José A. Pastor Ridruejo, Curso de Derecho Internacional Publico y Organizaciones Internacionales, Madrid, Editorial Tecnos, 1992, p.207-217.

R. Fac. Direito, Curitiba, a.28, n.28, 1994/95, p.141-148 
dição ou outro órgão internacional. Se o indivíduo é vítima de uma violação de Direito Internacional Público, deve reclamar no plano interno do Estado infrator. Se não obtém satisfação, deve recorrer ao Estado de sua nacionalidade para que este faça a reclamatória, diretamente, ou ante um órgão internacional competente. Exercita-se assim a proteção diplomática.

Entretanto, no período logo após a Segunda Guerra Mundial, quando agressões aos direitos e liberdades inerentes aos seres humanos foram cometidas pelas atrocidades e horrores daquela época, um interesse internacional em promover e encorajar o respeito pelos direitos humanos emergiu e um plano internacional de ação positiva foi reivindicado. Direitos humanos passaram a integrar as exigências mais elementares de convivência na sociedade internacional. Com a Carta das Nações Unidas de 1945, houver a necessidade de se criar recursos ante instâncias internacionais de controle e garantia, não só de promoção, mas também de proteção dos direitos humanos. O Direito Internacional Público contemporâneo apresenta caráter humanista e social. institucionalizado e democrático onde a promoção e proteção dos direitos humanos ganha espaço cada vez maior na construção de mecanismo voltados à busca de uma paz positiva e dinâmica que não só exclui a guerra, mas que também tenta minimizar as injustiças individuais e sociais.

Normas imperativas de Direito Internacional Público, os direitos humanos constituem-se em ius cogens internacional, ou seja, normas aceitas e reconhecidas pela comunidade internacional dos Estados como as que não admitem acordo em contrário e que só podem ser modificadas por uma norma posterior de Direito Internacional Público que tenha o mesmo caráter. E uma das características da norma imperativa é a necessidade de cumprimento de obrigações erga omnes pois dizem respeito a interesses que transcendem a dos Estados soberanos e que se constituem em grandes temas de Direito Internacional Público.

Assim, criando condições mais favoráveis para o indivíduo no plano internacional através das transformações experimentadas nas últimas décadas pelo Direito Internacional Público, søiia o particular sujeito desta estrutura internacional? Teria o indivíduo o reconhecimento de uma certa subjetividade pela ordem internacional com legitimidade para reclamar pelo incumprimento de uma norma internacional perante os tribunais internacionais ou incorrer em responsabilidade internacional na infringência dos dispositivos internacionais? 
Segundo Professor J.F. Rezek, ${ }^{2}$ não têm personalidade jurídica de direito internacional os indivíduos. Para o autor, a proposição do indivíduo como sujeito de direito das gentes pretende fundar-se na assertiva de que certas normas internacionais criam direitos para as pessoas comuns, ou thes impõem deveres. Entende, portanto, que os indivíduos, diversamente dos Estados e das organizações, não se envolvem, a título próprio, na produção do acervo normativo internacional, nem guardam qualquer relação direta e imediata com esse corpo de normas. Não há titularidade de direitos e deveres, ou seja, para que a idéia da personalidade jurídica do indivíduo em direito das gentes pudesse fazer algum sentido, seria necessário que ele dispusesse da prerrogativa ampla de reclamar, nos foros internacionais, a garantia de seus direitos, e que tal qualidade resultasse de norma geral, o que, segundo Rezek, não acontece. Complementa ainda que, os raríssimos foros internacionais acessíveis a indivíduos são-no em virtude de um compromisso estatal tópico, e esse quadro pressupõe a existência, entre o particular e o Estado co-patrocinador do foro, de um vínculo jurídico de sujeição, em regra o vínculo de nacionalidade. Como exemplo, coloca que se a Itália entendesse de retirar-se das Comunidades Européias, súditos italianos não mais teriam acesso à Corte de Luxemburgo, nem cidadãos ou empresas de outros países comunitários ali poderiam cogitar de demandar contra aquela república.

Por outro lado, Professor Ridruejo ${ }^{3}$ entende que, aos dias de hoje, cabe ao indivíduo uma pequena parcela de subjetividade internacional limitada que tem lugar dentro de marcos convencionais.

Segundo o autor, os destinatários do Direito Internacional Público seriam os Estados, algumas vezes as organizações internacionais e excepcionalmente os súditos dos Estados. Embasa o seu posicionamento no surgimento de uma estrutura internacional nova que possibilita o conhecimento de reclamações de indivíduos que se consideram vítimas de uma violação pelo Estado infrator na esfera internacional, através de mecanismos criados pela ONU, no caso, o Protocolo Facultativo do Pacto de Direitos Civis e Políticos, ņelo Conselho da Europa através da Convenção

2 José Francisco Rezek, Direito Internacional Público - Curso elementar, São Paulo, Editora Saraiva, 1991.

3 José A. Pastor Ridruejo, Curso de Derecho..., op. cit., p. 207 - 217.

R. Fac. Direito, Curitiba, a.28, n.28, 1994/95, p.141-148 
Européia de Direitos Humanos e pela Organização dos Estados Americanos em razão da Convenção Americana de Direitos Humanos. E nessas estruturas, o revolucionário seria a possibilidade do indivíduo em reclamar contra o seu próprio Estado frente à ordem internacional.

Acrescenta ainda a questão da subjetividade passiva do particular frente ao Direito Internacional Público, tendo em vista a responsabilidade internacional do individuo pelos delitos internacionais como a pirataria marítima, genocídio, violação de direitos de guerra, ou seja, crimes contra a humanidade. Entretanto, complementa que na maior parte dos casos a determinação e imposição das penas se deixam comumente aos sistemas jurídicos internos.

Diante de dois posicionamentos antagônicos e, embora de maneira bastante suscinta, desenvolvido será neste trabalho a questão da evolução dos mecanismos de promoção e proteção aos direitos humanos, com o intuito de se verificar a posição do indivíduo frente ao Direito Internacional Público.

Primeiramente, os instrumentos que concedem ao indivíduo o acesso aos foros internacionais são a Convenção Européia de Direitos Humanos, assinada em Roma-Itália no ano de 1950 com entrada em vigor em 1953 sob os auspícios do Conselho da Europa, a Convenção Americana de Direitos Humanos, adotada em São José-Costa Rica no ano de $1969 \mathrm{com}$ entrada em vigor em 1978 pela Organização dos Estados Americanos, e o Pacto de Direitos Civis e Políticos, através do Protocolo Facultativo, elaborado pela Organização das Nações Unidas em 1966 cuja entrada em vigor se deu em 1976. Tais instrumentos facultam aos indivíduos que se consideram prejudicados por uma violação dos direitos enunciados nos textos a apresentar uma comunicação formal frente à ordem internacional. Entretanto, algumas diferenças devem ser apontadas.

O surgimento da Convenção Européia de Direitos Humanos se deu em razão de uma reação contra os regimes nazista e fascista tendo em vista as violações em larga escala aos direitos humanos que prevaleciam à época. Uma solução tinha de ser encontrada e aí a necessidade da criação de um mecanismo não apenas de promoção, mas também de proteção aos direitos humanos.

Assim, entrando em vigor a Convenção Européia de Direitos Humanos, qualquer pessoa ou grupo de pessoas, ou qualquer entidade não-gover- 
namental que tenha sofrido uma agressão ou tenha genuíno interesse pessoal no término da violação, a partir de então, pode registrar junto ao Conselho da Europa petições contendo denúncias de violações dos direitos e liberdades estabelecidas no texto da Convenção. Entretanto, esta prerrogativa está sujeita a uma declaração do Estado-parte da Convenção reconhecendo a competência da Organização em receber tais reclamações, ou seja, necessário se faz o reconhecimento por parte do Estado-membro do direito de reclamações individuais.

Por sua vez, o sistema americano foi desenvolvido de acordo com as necessidades referentes às relações entre indivíduos e seus próprios países, como por exemplo, prisão arbitrária, detenção sem julgamento, tortura, ou seja, tudo que se relacionasse com os regimes ditatoriais existentes à época. A criação de um instrumento capaz de, ao menos, reduzir o número de violações, encontrou forma na Convenção Americana de Direitos Humanos. Igualmente ao instrumento europeu, qualquer pessoa ou grupo de pessoas, ou qualquer entidade não governamental pode registrar junto à Organização reclamações contendo denúncias de violações de direitos e liberdades estabelecidas no texto da Convenção. Mas ao contrário do sistema europeu, não se faz necessário ser a vítima ou ter qualquer interesse pessoal no caso para figurar como signatário da petição, ficando tal possibilidade aberta a qualquer cidadão membro dos Estados pertencentes à Convenção. Além disso, no plano americano não se exige declaração especial por parte do Estado membro em reconhecer a competência da Organização para receber denúncias de particulares, mesmo porque, na maioria das vezes, tais reclamações tem como titulares vítimas de seus próprios Estados.

Sob os auspícios da Organização das Nações Unidas, o Protocolo Facultativo do Pacto de Direitos Civis e Políticos viabiliza o acesso do indivíduo vítima de violação de direitos humanos à Corte Internacional de Justiça, através da manifestação de um consentimento opcional pelo Estado demandado.

Assim, uma série de direitos civis e políticos, bem como um mecanismo para a implementação desesses direitos são oferecidos aos particulares cidadãos dos Estados signatários dos instrumentos acima referidos. Pelo sistema europeu e pelo mecanismo oferecido pela $\mathrm{ONU}$, o direito de queixa do indivíduo resulta opcional por parte do Estado membro dos respectivos instrumentos, uma vez que necessário se faz uma declaração do Plenipotenciário em reconhecer a competência do Conselho da Europa e da ONU para

R. Fac. Direito, Curitiba, a.28, n.28, 1994/95, p.141-148 
receber a petição. Por outro lado, o direito do indivíduo de encaminhar uma reclamatória frente à OEA tem caráter obrigatório, tendo em vista a ausência da exigência de aceitação através de documento opcional por parte do Estado-membro.

Concluindo, a afirmativa de que os indivíduos não possuem titularidade de direitos e deveres na ordem internacional tendo em vista a ausência de prerrogativa ampla de reclamar nos foros internacionais não procede totalmente, mesmo nos sistemas previstos no Conselho da Europa e Organização das Nações Unidas frente à declaração opcional exigida dos Estadosmembros para o reconhecimento da titularidade dos particulares em reclamar perante um tribunal internacional. Realmente, há necessidade de um compromisso estatal em aceitar o indivíduo como titular de direitos e deveres, em razão da existência de um vínculo jurídico de sujeição entre o Estado e o particular nacional, vínculo este também existente na ordem interna dos próprios Estados. Entretanto, no momento em que o Estado concede ao indivíduo o direito de reclamar perante foros internacionais, este último passa a ser titular de direitos e obrigações internacionais.

O sistema americano difere neste ponto, o que vem a sugerir também a aceitação da teoria proposta por Ridruejo que alega pequena parcela de subjetividade internacional limitada do indivíduo. A sujeição do particular ao Estado é ainda menor, uma vez que o direito de reclamar em juízo internacional concedido ao indivíduo é de caráter obrigatório, face a ausência de declaração exigida pela Organização ao Estado-membro. Uma vez ratificado pelo Estado o tratado que deu vida à Convenção Americana de Direitos Humanos, o indivíduo nacional deste Estado passa a ser titular de direitos e obrigações internacionais de forma obrigatória. Evidentemente que a titularidade cessa no momento em que o Plenipotenciário se desliga do instrumento por ele ratificado.

Há que se fazer uma observação com relação ao exemplo levantado pelo Professor Rezek. Os três instrumentos até então, de maneira bastante suscinta, analisados, dizem respeito ao sistema de coordenação de soberanias voltados à proteção internacional de direites humanos. Desde o fim da Segunda Guerra Mundial, estudos vem sendo realizados no sentido de desenvolver cada vez mais uma proteção ao particular, na tentativa de minimizar abusos por parte dos Estados. 
Entretanto, as Comunidades Européias estão sedimentadas em um sistema de subordinação de soberanias face à ordem comunitária para a integração econômica que tem como alicerce o Direito Comunitário. Com caracteres diferenciados do Direito Internacional Público, além da aplicabilidade direta da norma comunitária frente à ordem interna dos Estados, o Direito Comunitário tem como destinatários não apenas os Estados-membros, mas também os particulares, estes também sujeitos à jurisdição comunitária. Como exemplo, em 1970 as autoridades aduaneiras italianas reclamaram a uma firma nacional exportadora de obras de arte, que havia vendido uma pintura a um cliente da Alemanha Federal, um imposto de $20 \%$ sobre o valor do quadro exportado, imposto este previsto por uma lei anterior à guerra e que, embora contrária ao direito comunitário, nunca havia sido revogada pelo Parlamento Italiano. O exportador em causa pagou o imposto mas reclamou perante o Tribunal de Turim o seu reembolso, alegando que lhe fora exigido em violação de normas comunitárias que às autoridades italianas cumpria observar e ao tribunal italiano aplicar. O juiz italiano chamado a decidir solicitou então ao tribunal comunitário de Luxemburgo, ao abrigo do artigo 177 do Tratado da Comunidade Econômica Européia, que este declarasse se a disposição do tratado de Roma que impõe aos Estados-membros a supressão de direitos aduaneiros e encargos de natureza equivalente sobre as exportações, confere aos particulares, agentes econômicos da Comunidade, direitos que às jurisdições nacionais cumprem salvaguardar. O Tribunal de Luxemburgo respondeu afirmativamente sobre a aplicabilidade direta da norma comunitária na esfera interna do Estado-membro e, assim, o Tribunal de Turim ordenou a restituição ao exportador italiano do imposto indevidamente cobrado. ${ }^{4}$ Assim, além da estrutura comunitária referente a aplicabilidade direta da norma internacional frente à ordem interna dos Estados seja diversa daquela prevista no Direito Internacional Público, os destinatários naquele sistema de subordinação de soberanias à ordem comunitária são indiscutivelmente não apenas os Estados mas também o particular, titular de direitos e obrigações.

4 João Mota de Campos, Direito Comunitário, vol. II, Lisboa, Fundação Calouste Gulbenkian, 1990, p.208-209.

R. Fac. Direito, Curitiba, a.28, n.28, 1994/95, p.141-148 
Finalizando, interesses que transcendem os dos Estados soberanos, direitos humanos constituem-se hoje num grande tema de Direito Internacional Público, onde o indivíduo, aos poucos, vai ganhando cada vez mais espaço na estrutura internacional. Interessante seria a análise da praxis dos instrumentos levantados para verificação da efetividade de tais mecanismos.

\section{Referências Bibliográficas}

CAMPOS, João Mota de. Direito Comunitário. $3^{\mathrm{a}}$ edição. vol. II, Lisboa: Fundação Calouste Gulbenkian, 1990.

DURÃES, Beatriz Schiffer. "Convenção Européia de Direitos Humanos e Convenção Americana de Direitos Humanos em Comparação". in: Revista da Faculdade de Direito da Universidade Federal do Paraná. Curitiba. 1986 (23), p.51-72.

REZEK, José Francisco. Direito Internacional Público - Curso elementar. $2^{a}$ edição. São Paulo: Editora Saraiva, 1991.

RIDRUEJO, José A. Pastor. Curso de Derecho Internacional Publico y Organizaciones Internacionales. $4^{\mathrm{a}}$ edição. Madrid: Editorial Tecnos, 1992. 